\title{
CRIA E TERMINAÇÃO DE CORDEIROS CONFINADOS ${ }^{1}$
}

\author{
GROWING AND FINISHING OF FEEDLOT LAMBS
}

\section{Cleber Cassol Pires ${ }^{2}$, Lisiane Furtado da Silva $^{3}$, Fábio Eduardo Schlick ${ }^{3}$, Daniela Petri Guerra ${ }^{4}$, Geórgia Biscaino $^{4}$, Rejane Migotto Carneiro ${ }^{4}$}

\section{RESUMO}

O experimento foi realizado com o objetivo de avaliar o ganho de peso, o consumo de matéria seca e conversão alimentar de cordeiros confinados e abatidos com 28 ou $33 \mathrm{~kg}$ bem como de suas mães, até o desmame. Foram utilizados 22 cordeiros machos inteiros, filhos de carneiros Texel e ovelhas cruzas (Texel e Ideal). Os cordeiros foram confinados em baias individuais, com suas respectivas mães, até o desmame (45 dias de idade). Neste período, a alimentação fornecida visava a atender as necessidades nutricionais da mãe, e estava constituída de $70 \%$ de volumoso e $30 \%$ de concentrado. A partir do desmame, a dieta oferecida visava a atender as exigências nutricionais dos cordeiros, tendo sido constituída por $60 \%$ de volumoso e $40 \%$ de concentrado. Os valores encontrados para ganho de peso diário, consumo diário de matéria seca kg/animal, \% PV e g/UTM) e conversão alimentar, não diferiram $(P>0,05 \%)$ entre os pesos de abates estudados. Como média, obtiveram-se os seguintes resultados: $0,245 \mathrm{~kg} ; 0,712 \mathrm{~kg} ; 2,99 \% ; 66,02 \mathrm{~g}$ e 4,32, respectivamente.

Palavras-chave: confinamento, conversão alimentar, ganho de peso, ovelhas, ovinos.

\section{SUMMARY}

The experiment was carried out with the objective to evaluate the weight gain, dry matter intake and food conversion of feedlot lambs and slaughtered at 28 or $33 \mathrm{~kg}$ and of their mothers until weaning. Twenty-two intact male lambs, sired by Texel males, from crossbreed Texel-Ideal dams were used. The lambs were confined in individual stall together, with their respective mothers until weaning (45 days of age). During this period, each pair was fed to fit the mothers' nutricional requirements. The diet contained $70 \%$ of roughage and $30 \%$ of concentrate. From weaning on, the diet was formulate to provide the nutricional requirements of the lambs, and contained $60 \%$ of roughage and $40 \%$ of concentrate. The values obtained for weight gain, dry matter intake (kg/animal/day; \% live weight and g/metabolic size) and food conversion of lambs, did not differ $(P>0.05)$ among the weights of slaughter, the means obtained were $0.245 \mathrm{~kg}, 0.712 \mathrm{~kg} ; 2.99 \%$; $66.02 \mathrm{~g}$ e 4.32 , respectively.

Key words: confinement, ewe, food conversion, sheep, weight gain.

\section{INTRODUÇ̃̃O}

$\mathrm{O}$ alto potencial produtivo dos ovinos e o crescente mercado consumidor de carne ovina de qualidade são fatores que estimulam a realização de pesquisas com ovinos no Brasil. Os trabalhos científicos demonstram que a intensificação da produção promove um incremento nos índices produtivos existentes, além de garantir ao consumidor um produto de alta qualidade. Segundo OSÓRIO et al. (1998), na intensificação da produção ovina devem ser melhoradas as áreas de sanidade, alimentação, manejo reprodutivo, instalações e gestão da empresa, sendo preciso encontrar os níveis mais adequados para cada caso.

A produção de carne ovina apresenta-se como uma atividade alternativa, capaz de adicionar renda aos negócios, não só dos ovinocultores em si, mas à atividade rural como um todo, independente de se ter ou não tradição na criação de ovinos. $O$ cordeiro é a categoria animal que fornece carne de melhor qualidade e apresenta, nessa fase, os maiores rendimentos de carcaça e maior eficiência de produ-

\footnotetext{
${ }^{1}$ Parte da Dissertação de Mestrado em Zootecnia apresentada pelo segundo autor à Universidade Federal de Santa Maria (UFSM).

${ }^{2}$ Professor Titular do Departamento de Zootecnia, UFSM, 97105-900 - Santa Maria, RS. E-mail:cpires@ccr.ufsm.br. Autor para correspondência.

${ }^{3}$ Zootecnista MSc., UFSM, Departamento de Zootecnia.

${ }^{4}$ Alunas de graduação em Zootecnia, UFSM.
} 
ção, devido a sua alta velocidade de crescimento. Dentre outras alternativas eficazes para terminação dos mesmos, o confinamento tem despertado o interesse dos ovinocultores.

Além da idade, outros fatores como raça, peso de abate e alimentação influenciam no produto final. COTTERILL \& ROBERTS (1979), trabalhando com três raças paternas (Poll Dorset, Suffolk e Lincoln), verificaram que a taxa de ganho de peso médio é maior antes do desmame do que depois, e nos dois períodos, a raça Suffolk apresentou os maiores valores e a Lincoln os menores Os mesmos autores, ajustando os dados para plano nutricional baixo e alto, encontraram taxas de ganho de peso maiores, antes e depois do desmame, para o nível alto de nutrição. Comparando machos inteiros e fêmeas, desmamados com pesos entre 13 e $18 \mathrm{~kg}$, WYNN \& THWAITES (1981) verificaram que machos inteiros apresentam maior taxa de ganho de peso antes e depois do desmame, e chegam com menor idade ao peso de abate. CARVALHO et $\boldsymbol{a l}$. (1999a) verificaram que machos inteiros apresentam maior taxa de ganho de peso, seguidos por castrados e fêmeas.

O trabalho objetivou avaliar o ganho de peso das ovelhas e cordeiros, bem como o consumo e conversão alimentar do conjunto ovelha + cordeiro (mãe e filho), do nascimento ao abate e o consumo e a conversão alimentar dos cordeiros do desmame ao abate e o ganho de peso dos mesmos do nascimento ao abate.

\section{MATERIAL E MÉTODOS}

O experimento foi conduzido no Setor de Ovinocultura, do Departamento de Zootecnia da Universidade Federal de Santa Maria (UFSM). O trabalho foi realizado de julho a dezembro de 1997. Foram utilizados 18 cordeiros machos inteiros, filhos de carneiros Texel e ovelhas cruza (Texel $\mathrm{x}$ Ideal), aleatoriamente distribuídos nos tratamentos, que estavam constituídos por pesos de abates de $28 \mathrm{e}$ $33 \mathrm{~kg}$. À medida que nasciam, os cordeiros foram alojados com suas respectivas mães em baias individuais com área de $4 \mathrm{~m}^{2}$, permanecendo assim até o desmame, ocasião em que a ovelha era retirada. As baias foram providas de comedouro e bebedouro e apresentavam piso constituído de ripas, distante um metro do solo.

O período experimental foi precedido de 15 dias para adaptação das ovelhas à alimentação. Nesse período, as ovelhas receberam na forma de suplementação a mesma alimentação que foi oferecida no período experimental. Os animais foram pesados no $23^{\circ}$ dia após o início do experimento, ao desmame (45 dias de idade), e a partir deste, no intervalo de 21 dias. Este intervalo foi reduzido, à medida que os cordeiros se aproximavam do peso de abate. As pesagens intermediárias foram realizadas sem jejum prévio e, para as finais (peso de abate), foi realizado jejum de sólidos de doze horas. Até o desmame, foi calculado o ganho de peso médio diário para os 18 cordeiros confinados; a partir do desmame, o ganho de peso médio diário foi calculado para 12 cordeiros.

Foram utilizadas duas dietas, ambas foram calculadas de acordo com o NRC (1985), tendo sido a primeira balanceada para as primeiras seis semanas de lactação de ovelhas pesando $50 \mathrm{~kg}$ com parto simples, e a segunda para cordeiros desmamados, pesando $20 \mathrm{~kg}$ e para ganho de peso de $300 \mathrm{~g} / \mathrm{dia}$. A relação volumoso : concentrado, na matéria seca, utilizada foi de 70:30 para a primeira dieta e 60:40 para a segunda. Os animais eram alimentados às $8 \mathrm{~h}$, e pela tarde, às $17 \mathrm{~h}$. Ajustava-se, pela manhã, a quantidade de alimento a ser oferecido, em função das sobras do dia anterior, sendo que estas deveriam ser de $20 \%$ da quantidade oferecida, de modo a garantir o consumo voluntário dos animais. Registrou-se, diariamente, a quantidade de alimento oferecido, bem como as sobras, que foram amostradas e congeladas para análises de laboratório (matéria parcialmente seca e matéria seca).

O peso de corpo vazio (PCV) foi obtido através da diferença entre o peso de abate e o conteúdo gastrintestinal; e a transformação de peso inicial (ao nascimento) em peso de corpo vazio inicial foi feita através do coeficiente entre peso de abate e peso de corpo vazio. Utilizaram-se para isso, quatro cordeiros abatidos ao nascimento, sendo que o coeficiente obtido com os referidos dados foi 1,044882.

Empregou-se o delineamento experimental inteiramente casualizado com dois tratamentos e seis repetições, seguindo o modelo matemático: Yij $=\mu+\mathrm{Ti}+\Sigma \mathrm{ij}$, em que: Yij = observação $\mathrm{j}$ do animal que recebeu o tratamento $\mathrm{i} ; \mathrm{Ti}=$ efeito do tratamento i ; $\Sigma \mathrm{ij}=$ erro aleatório associado a cada observação. As análises estatísticas foram realizadas, utilizandose o programa estatístico SAS (SAS, 1990), sendo os dados submetidos à análise de variância .

\section{RESULTADOS E DISCUSSÃO}

Os valores médios para peso ao início do experimento (PI), peso ao desmame (PD), ganho de peso médio diário do parto ao desmame (GPMD) e ganho do parto ao desmame (GT) das ovelhas são apresentados na tabela 1 . Observa-se que não houve diferenças significativas $(\mathrm{P}>0,05)$ para nenhuma das variáveis estudadas, uma vez que as ovelhas recebe- 
Tabela 1 - Valores médios, em kilogramas, para peso após o parto (PI), peso ao desmame (PD), variação diária de peso do nascimento ao desmame (GPMD) e variação total (GT) das ovelhas, de acordo com os tratamentos.

\begin{tabular}{lcccl}
\hline \multirow{2}{*}{ Tratamento } & PI & PD & GPMD & GT \\
& & & & \\
\hline & & & & \\
$28 \mathrm{~kg}$ & 46,70 & 44,10 & $-0,058$ & $-2,6$ \\
$33 \mathrm{~kg}$ & 45,41 & 42,91 & $-0,055$ & $-2,5$ \\
& & & & \\
Média & 46,05 & 43,50 & $-0,056$ & $-2,55$ \\
F & 0,21 & 0,13 & 0,00 & 0,00 \\
P $>$ F & 0,6566 & 0,7191 & 0,9519 & 0,9519 \\
& & & & \\
\hline
\end{tabular}

ram o mesmo tratamento do parto ao desmame dos cordeiros.

Verifica-se que no período de aleitamento as ovelhas perderam, em média, $5,33 \%$ do peso após o parto, o que corresponde a uma perda de peso diário de - 0,056kg. Resultados que estão de acordo com o NRC (1985), o qual indica que nas primeiras oito semanas de lactação as ovelhas de parto simples com 40 a $50 \mathrm{~kg}$ de peso vivo apresentam uma perda diária de $0,050 \mathrm{~kg}$. Por outro lado, os resultados encontrados são discordantes dos verificados por CARVALHO et al. (1999b), os quais observaram um ganho de peso médio diário de $0,025 \mathrm{~kg}$ para ovelhas alimentadas em pastagem ou com silagem + concentrado, desde a parição até 50 dias após o parto.

A perda de peso das matrizes no presente trabalho foi ínfima quando comparada as que ocorrem em ovelhas mantidas em campo nativo durante a lactação, quando se verificam perdas significativas que impossibilitam a rápida recuperação, comprometendo qualquer pretensão de um processo intensivo de reprodução, ou seja, três partos durante dois anos. Segundo SUSIN (1996), ovelhas normalmente perdem peso durante $o$ início da lactação, no entanto, a magnitude dessa perda varia, dependendo da qualidade e quantidade do alimento disponível, do número de cordeiros amamentados, de fatores ambientais e do potencial produtivo da ovelha. A autora acrescenta que o balanço energético negativo, que ocorre nessa fase, pode afetar adversamente a produção de leite, o crescimento dos cordeiros e o subseqüente desempenho reprodutivo, especialmente quando se trabalha com programas reprodutivos visando a mais de uma parição anual. As ovelhas do presente trabalho apresentaram uma boa condição corporal na lactação que lhes permitiu uma rápida recuperação orgânica, e atingir pesos e condição corporal para o encarneiramento logo em seguida.

Na tabela 2, são apresentados os valores médios para peso inicial em $\mathrm{kg}$ ou ao nascimento (PI), peso ao desmame (PD), peso ao abate (PA), ganhos de peso médios diários (GPMD), ganho de peso de corpo vazio diário e permanência no confinamento (D), por tratamento. O peso médio de corpo vazio para o tratamento de $28 \mathrm{~kg}$ foi de 25,48 e para o tratamento de $33 \mathrm{~kg}$ foi de $28,33 \mathrm{~kg}$. O peso ao nascimento está diretamente relacionado com fatores de ordem genética e a nutrição da ovelha gestante, enquanto que o peso ao desmame depende principalmente da produção de leite da ovelha e da disponibilidade de alimentos sólidos ao cordeiro. Os valores médios encontrados de 4,90kg (PI) e 19,94kg (PD), são semelhantes aos de OLIVEIRA et al. (1996) que verificaram para cordeiros da raça Texel em campo nativo, valores médios de $4,6 \mathrm{~kg}$ para peso ao nascimento e $21,8 \mathrm{~kg}$ para $\mathrm{PD}$ aos 75 dias, e aos de CARVALHO et al. (1999a), que ao utilizar cordeiros $3 / 4$ Texel, observaram pesos de $4,16 \mathrm{~kg}$ (PI) e $19,98 \mathrm{~kg}$ (PD) aos 50 dias. No entanto, é importante ressaltar que os animais do presente trabalho foram desmamados mais jovens (45 dias).

Com relação à permanência no confinamento, observou-se diferença $(\mathrm{P}<0,01)$ entre os tratamentos, sendo que para atingir o peso médio de abate de $32,57 \mathrm{~kg}$, os cordeiros levaram 25 dias a

Tabela 2 - Valores médios para peso inicial (PI), peso ao desmame (PD), peso ao abate (PA), em kg, ganho de peso médio diário do nascimento ao desmame (GPMDA), do desmame ao abate (GPMDB), do nascimento ao abate (GPMDT), ganho de peso de corpo vazio (GPCV) em $\mathrm{kg} / \mathrm{animal} / \mathrm{dia}$ e permanência no confinamento (D), em dias.

$\begin{array}{lllllllll}\text { Tratamentos } & \text { PI } & \text { PD } & \text { PA } & \text { GPMDA } & \text { GPMDB } & \text { GPMDT } & \text { GPCV } & \text { D } \\ & & & & & & & & \\ 28 \mathrm{~kg} & 5,00 & 20,75 & 28,30 & 0,350 & 0,165 & 0,254 & 0,226 & 93,17 \\ 33 \mathrm{~kg} & 4,81 & 19,14 & 32,90 & 0,322 & 0,187 & 0,237 & 0,201 & 118,33 \\ \text { Média } & 4,90 & 19,94 & 30,60 & 0,336 & 0,176 & 0,245 & 0,213 & 105,75 \\ & & & & & & & & \\ \text { F } & 0,42 & 1,48 & 20,91 & 1,09 & 0,73 & 0,95 & 2,34 & 13,71 \\ \text { Pr>F } & 0,5244 & 0,2429 & 0,0010 & 0,3110 & 0,4141 & 0,3536 & 0,1573 & 0,0041 \\ \text { C.V. }(\%) & 12,55 & 13,64 & 5,69 & 16,20 & 24,11 & 11,98 & 13,35 & 11,33\end{array}$

Ciência Rural, v. 30, n. 5, 2000. 
mais. Os resultados mostram maior velocidade de ganho do nascimento ao desmame, em média 0,336kg GPMDA. Desse momento até o desmame, ocorreu uma acentuada diminuição do ganho de peso diário, ou seja, $52,38 \%$ do ganho obtido no período anterior. Após o desmame, o GPMD depende principalmente da adaptação dos animais à alimentação sólida e da qualidade da dieta.

COTTERILL \& ROBERTS (1979) constataram, para as raças Poll Dorset, Suffolk e Lincoln, valores de 0,198 e $0,130 \mathrm{~kg} ; 0,209$ e $0,129 \mathrm{~kg}, 0,187$ e $0,118 \mathrm{~kg}$ para GPMD antes e após o desmame, respectivamente. WYNN \& THWAITES (1981) observaram para cordeiros Merino e cruzados, valores de 0,246 e $0.331 \mathrm{~kg}$ de GPMD antes do desmame e de 0,134 e $0,171 \mathrm{~kg}$ após o desmame, respectivamente. OLIVEIRA et al. (1996) verificaram que cordeiros Texel em campo nativo apresentaram 0,229kg de GPMD no período pré-desmame e $0,068 \mathrm{~kg}$ de GPMD no pós-desmame. Num estudo recente, CARVALHO et al. (1999a) verificaram, para machos inteiros confinados, um GPMD de $0,316 \mathrm{~kg}$ antes do desmame e $0,159 \mathrm{~kg}$ após o desmame. Os ganhos de peso dos cordeiros (Tabela 2) do nascimento ao desmame são superiores aos obtidos nos trabalhos acima mencionados. Os trabalhos citados também mostram uma queda acentuada do ganho pós-desmame, conforme observou-se na presente pesquisa.

Na tabela 2, observa-se que o PI dos cordeiros, em média 4,90kg, representa $16 \%$ do peso médio de abate, enquanto o PD (45 dias) representa $65 \%$. O aumento de peso do nascimento ao desmame foi em média de $15,04 \mathrm{~kg}$, o que corresponde a $49 \%$ do peso médio de abate, e do desmame ao abate foi de $10,66 \mathrm{~kg}$, ou seja, $35 \%$ do peso de abate. O tempo médio do desmame ao abate foi de 60 dias. Esses dados e os de ganho de peso mostram que os ótimos resultados obtidos do nascimento ao desmame praticamente se diluem, em função do baixo desempenho dos cordeiros após o desmame, apesar do fornecimento de uma dieta compatível com as exigências nutricionais dos animais. Esse fato pode nos indicar que o cordeiro precisa ser melhor preparado para ser desmamado em idade muito jovem.

Quanto ao GPCV, observam-se maiores valores numéricos para os animais abatidos com menor peso (mais jovens) em relação aos mais pesados. Os valores para consumo de matéria seca (MS) diária, para $100 \mathrm{~kg}$ de peso vivo (\%PV) e em função do tamanho metabólico (g/UTM), e a conversão alimentar (CA), do conjunto ovelha + cordei- ro do nascimento ao desmame (45 dias de idade), são apresentados na tabela 3 e para os cordeiros, do desmame ao abate, são apresentados na tabela 4. Na tabela 3, o consumo de MS foi calculado em função do peso médio do conjunto ovelha + cordeiro e a $\mathrm{CA}$, em função da quantidade de $\mathrm{MS}(\mathrm{kg})$ consumida pelo conjunto, para que houvesse $1 \mathrm{~kg}$ de ganho de PV do cordeiro.Verifica-se que para todas as variáveis estudadas, tanto para o conjunto ovelha + cordeiro (Tabela 3) como para os cordeiros (Tabela 4), não houve diferença significativa entre os tratamentos $(\mathrm{P}>0,05)$.

O conjunto ovelha + cordeiro apresentou, em média, maior consumo em \% PV $(3,48 \%)$ e em relação ao tamanho metabólico $(83,12 \mathrm{~g} / \mathrm{UTM})$, do que os cordeiros, para os quais os valores encontrados foram 2,99\% e 66,02g/UTM, respectivamente. Quanto a CA, observa-se que o melhor resultado foi encontrado para os cordeiros $(4,32)$ em relação ao conjunto ovelha + cordeiro, no qual o valor médio verificado foi de 5,96.

Os resultados médios, para consumo diário de MS e CA, do conjunto ovelha + cordeiro (Tabela 3), foram superiores aos obtidos por CARVALHO et al. (1999a), os quais verificaram os seguintes valores: $1,46 \mathrm{~kg} /$ ovelha+cordeiro/dia e CA de 4,60: 1 .

Os dados médios diários, encontrados neste trabalho, para consumo de matéria seca dos cordeiros (Tabela 4), foram inferiores aos verificados por GARCIA \& SOBRINHO (1998) que, trabalhando com cordeiros dos 60 aos 135 dias de idade, obtiveram um consumo médio de 1,050kg/animal/dia e aos de PIRES et al. (1999) que observaram um consumo médio de MS de $0,828 \mathrm{~kg}$ para cordeiros Ideal e cruzados (Texel x Ideal) dos 3-4 meses aos 6-7 meses de idade. O consumo de

Tabela 3 - Valores médios para consumo diário de matéria seca (CMS) e conversão alimentar (CA) do conjunto ovelha + cordeiro, do nascimento ao desmame (45 dias de idade).

CMS

CA

\begin{tabular}{|c|c|c|c|c|}
\hline & (kg/ovelha+cordeiro/dia) & $(\% \mathrm{PV})$ & (g/UTM) & \\
\hline $28 \mathrm{~kg}$ & 2,048 & 3,52 & 84,72 & 6,00 \\
\hline $33 \mathrm{~kg}$ & 1,841 & 3,44 & 81,53 & 5,93 \\
\hline Média & 1,944 & 3,48 & 83,12 & 5,96 \\
\hline $\mathrm{F}$ & 1,61 & 0,23 & 0,57 & 0,01 \\
\hline $\operatorname{Pr}>\mathrm{F}$ & 0,2222 & 0,6402 & 0,4639 & 0,9123 \\
\hline $\mathrm{CV}(\%)$ & 17,78 & 9,70 & 10,50 & 20,48 \\
\hline
\end{tabular}


MS, no presente experimento, foi menor em relação aos citados acima, pois os cordeiros utilizados eram mais jovens e não possuíam o trato gastrintestinal totalmente desenvolvido, o que certamente influiu na quantidade de alimento consumido. No entanto, os valores foram superiores aos de CARVALHO $\boldsymbol{e t} \boldsymbol{a l}$. (1999a) que verificaram um consumo médio diário de $0,57 \mathrm{~kg}$ de MS, para cordeiros dos 50 aos 100 dias de idade.

Quando os valores de consumo são expressos em $100 \mathrm{~kg}$ de PV (\%PV), observa-se que o resultado médio, encontrado neste trabalho (2,99\%), é próximo dos obtidos por PILAR et al. (1994), os quais, trabalhando com borregos das raças Hampshire Down, Texel, Suffolk x Corriedale e Ile de France $x$ Corriedale, obtiveram como média de consumo 2,83\% PV; CARVALHO et al. (1999a) que verificaram valores médios de $2,41 \%$ e PIRES et al. (1999) que observaram um consumo médio de $3,25 \%$ do PV. Expressando os valores de consumo de matéria seca em UTM, observa-se que o valor médio, verificado neste trabalho (Tabela 4), é semelhante aos obtidos por PÈREZ et al. (1998), que trabalhando com cordeiros das raças Santa Inês e Bergamácia dos 100 aos 185 dias de idade, registraram como consumo médio 65,55g/UTM. Todavia, os resultados do presente trabalho foram superiores aos constatados por CARVALHO et al. (1999a), que verificaram consumo de 53,60g/UTM, para machos inteiros, 54,19g/UTM para machos castrados e $51,14 \mathrm{~g} / \mathrm{UTM}$ para fêmeas, $51,14 \mathrm{~g} / \mathrm{UTM}$ dos 50 aos 100 dias de idade. No entanto, os valores foram inferiores aos encontrados por PIRES et al. (1999), que obtiveram como valor médio $73 \mathrm{~g} / \mathrm{UTM}$ para cordeiros Ideal e cruzas, dos 3-4 aos 6-7 meses de idade.

Em relação à $\mathrm{CA}$, o índice médio de 4,32:1 (Tabela 4), é menor ao citado por PILAR $\boldsymbol{e t}$ al. (1994) que, trabalhando com borregos de cinco genótipos, obtiveram um valor médio de 6,18:1.

Tabela 4 - Valores médios para consumo diário de matéria seca (CMS) e conversão alimentar (CA) dos cordeiros, do desmame (45 dias de idade) ao abate.

\begin{tabular}{lllll} 
Tratamento & \multicolumn{3}{c}{ CMS } & CA \\
\cline { 2 - 4 } & \multicolumn{5}{c}{$(\mathrm{kg} /$ animal/dia $)$} & $(\% \mathrm{PV})$ & $(\mathrm{g} / \mathrm{UTM})$ \\
\hline & & & \\
$28 \mathrm{~kg}$ & 0,686 & 2,85 & 63,04 & 4,40 \\
$33 \mathrm{~kg}$ & 0,739 & 3,14 & 69,00 & 4,24 \\
Média & 0,712 & 2,99 & 66,02 & 4,32 \\
& & & & \\
$\mathrm{~F}$ & 3,55 & 1,07 & 1,42 & 0,09 \\
Pr>F & 0,0889 & 0,3249 & 0,2614 & 0,7710 \\
$\mathrm{CV}(\%)$ & 6,81 & 16,21 & 13,14 & 21,49 \\
& & & & \\
\hline
\end{tabular}

Também foram inferiores aos resultados de PÈREZ et al. (1998), que encontraram valores de CA de 6,26 para cordeiros Santa Inês e 6,05 para Bergamácia, e aos observados por PIRES et al. (1999), os quais verificaram médias de CA de 8,82 para cordeiros Ideal; 7,41 para cordeiros cruzas ( $1 / 2$ Texel x $1 / 2$ Ideal) e 7,81 para cordeiros (3/4 Texel x 1/2 Ideal). Esses resultados melhores de CA são explicados pela menor idade dos animais utilizados neste experimento. Entretanto, o valor médio de CA, encontrado neste trabalho $(4,32)$ foi próximo ao verificado por CARVALHO et al. (1999a) que, em condições semelhantes a deste trabalho, obtiveram um valor médio de 4,20:1 para cordeiros confinados dos 50 aos 100 dias de idade. Os dados de CA referidos na tabela 3 também foram melhores, quando comparados com os da literatura consultada.

\section{CONCLUSÃO}

A cria e a terminação de cordeiros em confinamento é um método eficiente na produção de carne ovina. O ganho de peso obtido pelo cordeiro do nascimento ao desmame não é sustentado pósdesmame até ao abate, o que indica a necessidade de se buscar alternativas para o melhor desempenho do cordeiro nesse período.

\section{REFERÊNCIAS BIBLIOGRÁFICAS}

CARVALHO, S., PIRES, C.C., PERES, J.R., et al. Desempenho de cordeiros machos inteiros, machos castrados e fêmeas, alimentados em confinamento. Ciência Rural, Santa Maria, v.29, n.1, p.129-133, 1999a.

CARVALHO, S., PIRES, C.C., BERNARDES, R.A.C., et al. Desempenho e produção de lã de ovelhas lactantes e ganho de peso e características da carcaça dos cordeiros. Ciência Rural, Santa Maria, v.29, n.1, p.149-153, 1999b.

COTTERILL, P.P., ROBERTS, E.M. Crossbred lamb growth and carcass characterstics of some Australian sheep breeds. Aust J Exp Agric Anim Husb, v.19, p.407-413, 1979.

GARCIA, C.A., SOBRINHO A.G.S. Desempenho e características das carcaças de ovinos alimentados com resíduo de panificação "biscoito". In: REUNIÃ̃ ANUAL DA SOCIEDADE BRASILEIRA DE ZOOTECNIA, 35, 1998, Botucatu. Anais ... Botucatu : SBZ, 1998. 634p. p.29-31.

NATIONAL RESEARCH COUNCIL (NRC). Nutrient requirements of sheep. 6.ed. Washington : National Academy, 1985. 99p.

OLIVEIRA, N.M., OSÓRIO, J.C.S., MONTEIRO, E.M. Produção de carne em ovinos de cinco genótipos: 1- Crescimento e desenvolvimento. Ciência Rural, v.26, n.3, p.467-470, 1996.

OSÓRIO, J.C.S., ASTIZ, C.S., OSÓRIO, M.T.M. et al. Produção de carne ovina: alternativa para o Rio Grande do Sul. Pelotas: UFPEL, 1998. $166 \mathrm{p}$.

PÉREZ, J.R.O., GARCIA, I.F.F., SILVA, R.H., et al. Desempenho de cordeiros Santa Inês e Bergamácia alimentados com diferentes níveis de dejetos de suínos. In: REUNIÃO ANUAL DA SOCIEDADE BRASILEIRA DE ZOOTECNIA, 35, 1998, Botucatu. Anais ... Botucatu : SBZ, 1998. 634p. p.173-175. 
PILAR, R.C., PIRES, C.C., RESTLE, J., et al. Desempenho em confinamento e componentes do peso vivo de diferentes genótipos de ovinos abatidos aos doze meses de idade. Ciência Rural, Santa Maria, v.24, n.3, p.607-612, 1994.

PIRES, C.C., ARAÚJO, J.R., BERNARDES. R.A.C., et al. Desempenho e características da carcaça de cordeiros de três grupos genéticos abatidos ao mesmo estágio de maturidade. Ciência Rural, Santa Maria, v.29, n.1, p.155-158;., 1999.
SAS / STATISCAL USER'S GUIDE. Version 6. 4. ed. Cary, NC, USA : SAS Institute Inc, 1990. V.1. p.890.

SUSIN, I. Nutrição de ovinos. Jaboticabal : FUNEP, 1996. Exigências nutricionais de ovinos e estratégias de alimentação :p.119-141

WYNN, P.C., THWAITES, C.J. The relative growth and development of the carcass tissues of merino and crossbred rams and wethers. Aust J Agric Res, v.32, p.947-956, 1981.

Ciência Rural, v. 30, n. 5, 2000. 